\title{
Interaction of Universal and Ethnocultural Codes in Structure of Advertisement Communication
}

\author{
Elena N. Ezhova*, Oksana A. Dvoenko \\ ${ }^{1}$ Department of advertising and public relations of the humanitarian institute of the North Caucasus Federal University, Stavropol, \\ Russia
}

\begin{abstract}
This work presents the systematized Russian and foreign scientific knowledge about the specific functioning of advertisement discourse in multiethnic society. The methodology of this research is based on the structural semiotic approach, functional analysis, an institutional-discourse method, an activity approach. The analysis of a big number of advertisement texts served the basis for typological classification of ethno cultural codes in the structure of media advertisement communication. The idea of this typology is heterogeneity advertisement texts, which are organized on the basis of the three semiotic systems: visual, verbal and acoustic. The understanding and realization of the idea of hybrid text modeling in the advertisement design allows one to improve its effectiveness, which results from the increase of the level of advertising information perception and the degree of its impact to the people. This demonstrates the importance of such professional qualities for advertisement specialists as the readiness and ability to work in multicultural society.
\end{abstract}

\section{Introduction}

Modern advertisement discourse is formed in the context of economical, social and political globalization in the society. This explains transcultural character of semiotic field of advertisement where we can see the convergence process of universal and local codes, ethno specific codes of various cultures. Universal codes in the structure of advertisement discourse have the idea of material and substantial ethic integrity of the society, the universal human values; local codes reflect the unique nature and the variety of cognitive national spheres which exist as a part of multicultural world. As a result, we can speak of hybrid modelling of the world image of media advertisement, which is founded on interaction of common and unique features.

The development of concept of multicultural codes in the structure of advertisement communication research is founded on the theoretical and methodological ideas taken from information and communication theory works (Bell D., Baudrillard J., Zemlyanova L. M., Luman N., Quayle D. Mac, McLuhan M., Popov V. D., Pocheptsov G. G., Habermas U. etc.), language conceptualization works (Alefirenko N. F., Arutunova N. D., $\quad$ Bahtin M. M., $\quad$ Vezhbitskaya A., Gachev G. D., Zaliznyak A. A., Krasnykh V. V., Lihachev D. S., Lotman Yu. M., Friedrich RosenstockHuessy O., Stepanov Yu. S., Telia V. N., Toporov V. N., Toffler E., Fukuyama F., Shmelev A. D.).

The works where advertisement is taken as sociocultural phenomena (Vikentiev I. L., Deyan A., Musykant V. L., Ogilvy D., $\quad$ Russell G. T,
Fedotova L. N., Feofanov O. A., etc.) and as an image producing system (Bart R., Ezhova E. N, Kovrizhenko M. K., Kostina A. V., Ovrutskiy A. V., Pendikova I. G., Rakitina L. S., Rumshina L. I., Starykh N. V., Starush M. I., Uchenova V. V., Fuko M., Yagodkina M. V.) are of great importance for our research.

Torben Vestergaard and Kim Schroeder's concepts about one-way communication of advertisement in contrast to other forms of mass communication are of great theoretical and methodological value for our research

Scientists are convinced that one-way communication of advertisement form, organized as interaction of verbal and non-verbal media, determines the factors that influence the choice of these media and the effectiveness of their work. [1].

Special attention should be paid to works dedicated to the issue of mass media culture phenomena in multiethnic context. The principles of multicultural policy in contemporary world are observed in works of the following scientists: Benhabib S., Bader V., Giddens A., Malahov V., Pokrovsky N., Tishkov V., etc. The advertisement phenomena in the context of multicultural society are observed in works of Egorova E. S. She resumes that the most important multicultural determinants in advertisement are such parameters as symbols, social code, value based views and standards, life style, etc. [2]. Shtukina E. N. finds out the special perception and effectiveness of advertisement texts, which work in heterogeneous linguocultural society [3]. Ksenzenko's works focus on the issue of 
effectiveness of advertisement communication in multicultural society according to the quality of conformance of the advertisement text parameters and value based views of the recipients [4].

The mythological aspect of the research is based on the structure-semiotic approach which includes consideration of the advertisement texts structure as a multivariate unity of semiotic codes of various cultures; functional analysis which is targeted at the research of specific functioning of various semiotic systems' elements in the structure of heterogeneous advertisement discourse; an institution-discourse method which implies advertisement communication analysis in the context of institutional status based type of discourse; an activity approach which is targeted at consideration of the policode text as a result of the advertisement manager creative activity in the context of multiethnic society. This creative activity is aimed at the recipient perception and the change of his behavior style.

\section{Results and Discussion}

The media advertisement discourse semiosis results from cultural marks and various denotative correlation interaction: national stereotypes, symbols, myths, archetypes. It is important to note that in the structure of advertisement texts these marks get additional meanings - they go through the system of customers' values and beliefs. This additional modelling is some kind of transformation of one model into a different one. This process has a great manipulative potential as it forms behavioral stereotypes of customers.

One does not normally see any text quotes of the source culture in the advertisement messages. It is done so because the key sense of advertisement messages should be easily and properly caught by target recipients. However there can also be an opposite situation when the quote is built on a complicated code and as a result the recipient cannot not recognize its key idea. This is the case when he plays some communicative game where he has to decode the messages in various layers with various meanings. Here one can find the process of contextual dialogue (between the advertisement message itself and its recipient) being covered with intertextual dialogue (between the advertisement message and the source of quotation). If the adequate decoding cannot be finally got (for example, when they use some unknown code from unfamiliar culture in the advertisement message), the advertisement does not work and it is of no use.

In general we can resume the intertextual focus of media advertisement discourse which is based on artefacts of proceeding cultures such as myths, folk stories, various forms of art (literature, music, art, architecture, cinema, decorative arts and crafts), historical texts, fashion and design, the source advertisement message, etc. The media advertisement text gets the features of a stereophonic structure, which is characterized by involvement into semiotic cultural environment on the basis of the dialogues/polemics with texts of past and present culture.
Structure-semiotic organization of advertisement text has two different-way impulses: on the one hand, impulses of repression, stability, static states; on the other hand, dynamic impulses, stereotype breaks, creativity [5]. To provide the proper perception of the information by the recipient, its media codes should be identic to the semiotic codes of the advertisement recipient's culture as well as to the cognitive and axiological constants, stereotypical models of sociocultural behavior [6]. To get the feedback and behavioral response from the recipient, the advertisement should make a breakout of stereotypes and value based standards, push something brand new into his worldview. The mechanism of the advertisement text modeling relates to the Festinger theory of cognitive dissonance. The idea of this theory is co-existence (and dissonance) of two opposing systems of knowledge, makes a person change his behavior and views in order to remove the tension caused by this dissonance [7]. The most frequent way to realize the invariant model of static and dynamic, stereotype and creativity in advertisement design conflicts is the binary opposition "familiarunfamiliar" which reflects the principle if sense making in all multiethnic cultures [8].

The presence of "familiar" mental substance in advertisement is targeted at actualization of the ethnocultural constants system, its primary purpose is to have subconscious impact which in its turn makes the process of advertisement decoding and perception as much easier as possible. The presence of "unfamiliar" mental substance which is interpreted by the advertisement recipient as "out of it" is targeted at activation of creative mind and starts the impulse which enriches the personal culture and helps to get more profound self identity understanding. It is very important to say that the positive correlation and interaction of "familiar" and "unfamiliar" codes can be got only in case if national and foreign national ideas do not oppose to each other.

Here are some examples. The strategy of interaction of "familiar" and "unfamiliar" forms the concept of advertisement of vodka "Russkiy led". The slogan "There is something Russian in everyone" conveys this concept. The key figure of the advertisement is Silvestre Stallone. The advertisement tells that his ancestors come from Russia. His advertisement image is the actualization of such traits as courage and heroic strength.

The strategy of cultural flow is the key idea of the set of social advertisement posters "Nasty immigrants". It was first presented at Moscow Festival of Social Advertisement in 2009

That advertising campaign was to actualize the problem typical for Moscow citizens and people from other Russian cities: the problem of intolerance to people of Caucasian and South Caucasian origin. The key target of advertisement was to break the stereotypes of immigrants image and to actualize the idea the negative feelings in them have absolutely no reason. The posters illustrated great people from those regions, their nationalities and their merits. "Prince Bagration. Grand General. Georgian"; "Sergey Dovlatov, Great Russian 
writer. Armenian"; "Arseny Tarkovsky. Famous film director. Nogai (Dagestan)"; Michael Tariverdiev. Composer ("17 Moments of Spring", "The Irony of Fate"). Armenian".

Russian culture is known for such features as "unlocked", opened for intercultural communication, ready for intense dialogues with different cultures. Moreover this dialogue is taken as the key resource of own cultural identity, originality opposed to other cultures. It is also considered as the resource of enrichment: the multiple ideas stimulate new forms of creative sense. M.M. Bahtin believes that it is the foreign culture that makes us search for answers to questions never asked before, we finally get these answers and this is our way to get new sense. [9]

This "unfamiliar" culture contact is aimed at imaginative abilities activation, creative potential of rational thinking; contact with native culture traditions is featured by representation of the cultural constants, the system of national values, behavioral stereotypes. It is, first of all, aimed at subconscious level things, and advertisement creators clearly know that its makes the process of advertisement perception and interpretation by the advertisement recipients much easier. Immergence into "native" cultural environment creates an associative link which is closely connected with present artefact of material and nonmaterial cultural aspects. All this somehow brings one in the past.

Our typology of ethnocultural codes in the structure of advertisement communication is based on the idea of heterogeneity of the advertisement text, which is organized as the interaction of the three semiotic systems: visual, verbal and acoustic.

I. Visual ethnocultural codes:

1) ethnonational symbols, myths and archetypes;

2) national heroes images (ethnic personal appearance features, national costume, stereotypical ethnocultural behavioral features);

3) story lines from national history;

4) illustration of national hallmarks - cultural objects;

5) illustration of national traditions - festivals, holidays, everyday life scenes;

6) national ornaments, type style, etc.

II. Verbal ethnocultural codes:

1) names of geographical places, names of ethnic groups, nationalities;

2) special linguistic features which is common for the culture;

3) phraseological units;

4) national speech patterns, proverbs, folk sayings, etc.

III. Acoustic ethnocultural codes:

1) imitation of oral folklore and national literature style genres (as a rule, syncretic verbal-acoustic code);

2) national music, rhythms;

3) national speech marks;

4) national sound marks, etc.

As a rule, visual ethnocultural codes in media advertisement communication are actualized via a special set of markers, which imitate the immersion into the definite ethno-cultural reality.
A good example of this kind of immersion is the advertisement of tea. The typical strategy here is that the advertisement object is involved into the tea party scene specific for some ethnocultural traditions (for example, Chinese, Indian, Ceylonese, English, Russian, etc). This strategy is the best choice because in most countries a tea party has ceremonial character and has specific national features. The "historical mark" becomes attractive for a consumer as it actualizes the unity of such components as the country of the product origin, its quality and also its production and consuming details.

We can provide commercials of the following tea trademarks: "Orimi Trade" ("Princess Gita", Princess Kandy", Princess Noori”), "Eastern Merchant", etc. as an example of actualization of oriental tea party traditions. The Chinese tea party markers are the emperor images and also the images of grand people, Chinese women with umbrellas and Chinese porcelain sets. The Russian tea party markers in advertisement are samovar, honey, jam, tea talks, etc. As we know the British were the first in Europe to start the tea party tradition. The British tea party markers are the images of smug ladies and gentlemen sitting by the fire or in the garden at the tea table covered with a snowy tablecloth and tea sets, tea-cosy pots, a jug for hot water, a milk jug, saucers with desserts, silver table ware, a strainer with a mat, a sugar bowl with sugar cubes, sugar nippers, etc. In Ahmad Tea advertisement, «real lovers of English tea" have the chance to win the pair trip to London where they can visit the Five o'clock ceremony.

A very remarkable ethnocultural code in the media advertisement world image is the illustration of loci which are marked with hallmarks. This type of visual codes is usually used in the advertisement of products and services associated with a certain territory; this is the case when the locus marking gets the status of the unique trade offer (UTO). As an example, the locus of Brazil can be the UTO in the advertisement of coffee. (Brazil is well-known as a place where they grow coffee of the best quality); the locus of Switzerland can be the UTO in watches (Switzerland is a well-known supplier of best quality), etc. In the advertisement of cars, it is a good idea to use the locus of Japan or Germany. So in Mitsubishi Lancer advertisement, the representative hallmark of Japan is the holy mountain Fudziyama: "Mitsubishi Lancer: Japan is close than one thinks... Mitsubishi Lancer is you true Japan".

Let us take the example of a printed version of advertisement of Chevrolet Lacetti: "Chevrolet plus Italian character of Lacetti makes you free. What do you know of the Italians? An Italian with one's hands bound back cannot speak. If an Italian cannot speak, he dies. What does all this have in common with Lacetti? Nothing! But if you need to tell about Chevrolet Lacetti you need three words: fast, maneuverable, design. As for the character - you'd better try it". "Italian" context is also taken in the visual text layer: the car is staged by the sea. This is motivated by the perception of Italy as the country surrounded with five seas: in the East - the Tyrrhenian and the Ligurian seas, in the South - the Ionian and the Mediterranean seas, in the East - the Adriatic sea. People call this car "Italian American of 
Korean production". This phrase was taken as the basic idea of the advertisement strategy built on both the affirmation and negation of the "Italian" theme: on the one hand, the car has the "Italian character", on the other hand, there is nothing "Italian" here. The Italian features are only visual as Italian studios Pininfarina and ItalDesign designed the hatchback and sedan. They did this for European customers. A comfortable and fashionable cabin is the key feature.

As for representation of "unfamiliar" ethno cultural features, apart from its direct function - mark of the locus of the production, the sphere of its usage - can also have another function. So for certain groups of products Russian people strongly believe that everything foreign is not "unfamiliar" or "unknown" but absolutely perfect, of much better quality than Russian and therefore much more attractive and simply the best. Of course, this does not work for some products, for example, food of Russian production is preferential: "Kvas is not Cola, drink "Nikola".

The "attractive" features of foreign culture, which cannot be found in Russian environment in advertisement, are often associated with magnetism of exotic things, they bring you to ethnic phenomena of "natural" (virgin nature, natural forms and substances, etc), they bring us to the past. Therefore, this ethnic concept is clearly viewed in the advertisement of "Bounty" which has a well-known and popular slogan ("These moments you cannot get the reality from the dream. Bounty....Paradise and delight...”). Visualization is represented by Exotic Island with crystal clear water of cyan color, a white sand beach and a palm forest, a girl in a swing enjoying Bounty. The slogan of this advertisement has been strongly put into Russian mind as the substantial way to get the key to paradise (when Russian tourists come to the Caribbean islands guides tell them that this commercial was filmed exactly there).

As mentioned above the examples of verbal ethnocultural codes in media advertisement communication are geographical names, loci names, nation names, nationalities; lexical unites specific for the certain culture; phraseological unites, national speech patterns; proverbs and sayings. These specific linguistic language elements have no word-by-word equivalents in other languages; they are closely connected with "key ideas" of the certain language world image [10]. In the advertisement they are used to show the national coloring and mental characteristics of a certain nation.

One of the most important "key ideas" of the Russian world image is the idea that Russian soul openness is the result of great outdoors of the country. This idea goes through most of Russian culture literature including mass culture. In media advertisement discourse, this idea is transformed into the point that open spaces are vitally important for a Russian person to keep internal comfort. V.N. Toporov supposes that Russian lexeme "space" is characterized by a unique semantic meaning and myphopoetical expressivity, it brings the strong idea of progressively increasing expansion, progress and advancement. Its internal form (Russian morphemes *pro-stor-: *pro-stirati) represents the meanings of "ahead, advance, outgo" - and then "openness, will"
[11]. Such ethno special for the Russian culture lexemes as "will, liberty, wide open, courage, etc. join lexeme "space" so that they form conceptual semantic correlation.

In Russian media advertisement discourse, lexeme "space" brings its linguo-specific content as well - it is the boundless, infinite space, the perception of this space by a Russian person launches the complex of emotional feelings: "it keeps you full not only of visual pleasure but also of hedonistic admiration and delight" [12].

As a good example, let us take the advertisement of Mercedes-Benz automobile: "Comfort dynamics. Being once in the spacy saloon, you find yourself in a real comfort. $<\ldots>$ You will feel perfect any road you try. Your choice of Mercedes-Benz means you're moving ahead". Lexeme "spacy" actualizes not only basic semes "not close" "not preventing movements" but it also has meanings of emotional coloring: calm and comfortable.

Russian media advertisement world image also reflects antithesis "space-cosiness" which is very common for Russian culture. It is good to note that lexeme "space" goes with outdoors and infinity meanings; however, lexeme "cosiness" stands for small, closed, settled and lived-in place. Space, on the one hand, and cosiness, on the other hand, become the two poles, which actualize associations with safe and calm conditions, guarantees against any break-ins and these associations are very common for Russian mentality. As a rule, in the structure of advertisement discourse, cosiness is associated with home, which is a symbol of warm and comfort, safety and family relations. This associative function is featured in the advertisement of "Baltika" bear, in the advertisement of MTS cell operator where you can see a family; they are having a New Year's party in a cosy house in a mountain wood.

In advertisement communication, the meaning of space correlates with meanings of will and liberty. Lots of scientist saw the linguo-specific feature of Russian lexeme "will" which includes the idea of pulling outside some certain restrictive formalities and the idea of some extensive different way searching out. (The synonymic lexeme is "freedom". Its sense is more common for western ideas of absence of any internal restrictions). In media advertisement discourse, "will" is used to give this idea of outside actions - outside external restrictions. The slogan in the advertisement of Volvo "For free people - Volvo!" is based on phraseological transformation of "to each his own". This phrase can be found in Russian proverbs "To each his own and worldly way" and "to each his own: let him take a spring tune on his own fiddle, and dance to it when he has gone".

A very expressive example of a text structured with a system of verbal ethnocultural codes is the advertisement of Mazda BT-50: "Mazda BT-50 holding campaign for bad roads! The number of fitted roads is increasing. We are bored with traffic lights and traffic jams. We are felling nostalgic for these real Russian funs: cross country driving, mud-locked roads bumps. Can you demonstrate your driving abilities or all you can do is to change lanes?" "Mud-locked roads", "boring things", "fun", "bumps". These words, linguo-specific for Russian culture, in the structure of advertisement texts 
become a text forming impulse which cause semantic isotopy of Russian featurism.

The examples of acoustic ethnocultural codes in media discourse are national music, rhythms, national speech marks, national sound marks. As we can see, the commercial of mayonnaise "Maheev" is based on transformation of the part $\mathrm{V}$ section of Pushkin A.S. novel "Evgeny Onegin": "Winter. The peasant, cheerful, went to Elabuga clearing the wood path. His horse has no sense of snow; it has the sense of mayonnaise. With no concern of blowing snow, he stopped at "Maheevskiy" place. They both know that "Maheev" is great mayonnaise". The Russian mentality takes these words as national.

Apart from visual, verbal and acoustic ethnocultural codes in the structure of media advertisement discourse, we can also see actualization of codes of semiotic systems, which are not directly used in media communication such as flavors and smells. They can also have some ethnocultural sense. All the abovementioned advertisement tools, when being identified, "start" the associative mechanism of the recipient's memory so that it gives the actualization of certain ethnocultural features.

\section{Conclusion}

The today's media advertisement process is formed under the globalization of present life; it reflects different way tendencies of modern culture. On the one hand, it is the tendency to draw universal human values to standards and norms; on the other hand, it is individualization and a great variety of national and cultural traditions. These tendencies should be taken into account in the process of advertising campaign work in multiethnic culture. The advertisement text structure based on the main ideas of hybrid modelling (balance between common and unique, universal and specific) allows increasing the recipient's level of advertisement information perception and cause desired cognitive and behavioral feedback.

That is why, every advertisement specialist should have such professional skills as readiness and ability to hold advertisement campaigns in multicultural society. There should be understanding and, following the specific features of advertisement, work on special national and cultural background as it allows one to avoid any cognitive dissonance in the process of advertisement text development and its adaptation to foreign cultures, which might result from the recipient's inability to decode some parts of information flow.

\section{References}

1. T. Vestergaard, K. Schroder, The Language of Advertising (Blackwell Publishers Ltd., Oxford, 1985)

2. E.S. Egorova, Modern problems of science and education 5 (2011)
3. E.E. Shtukina, Bulletin of Chelyabinsk State University. Ser. Philology and Art 23 175-180, (2008)

4. O.A. Ksenzenko, Mova and culture 12 202-208, (2009)

5. E.N. Ezhova, Media advertisement of the world: people and things (Ileksa, Moscow, 2010)

6. V.D. Popov, Social Informatics and Journalism (RAGS, Moscow, 2007)

7. L. Festinger, Theory of cognitive dissonance (Yuventa, Saint Petersburg, 1999)

8. V.V. Krasnykh, "His" among the "strangers": myth or reality (Gnozis, Moscow, 2003)

9. M.M. Bakhtin, Literary-critical articles (Fiction, Moscow 1986).

10. A.A Zaliznyak, Russian Linguistics 37 5-20 (2013)

11. V.N. Toporov, Studies on etymology and semantics (Languages of Slavic culture, Moscow, 2004)

12. A.A. Zaliznyak, Key ideas of the Russian language picture of the world (Languages of Slavic culture, Moscow, 2005) 